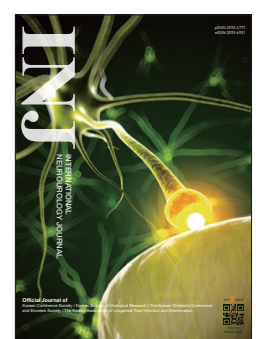

\title{
New Equipment and Devices for Therapeutic Purpose
}

\author{
Kwanwoo Shin (iD http://orcid.org/0000-0002-7563-8581 \\ Guest Editor \\ Department of Chemistry and Institute of Biological Interfaces, Sogang University, Seoul, Korea \\ E-mail: kwshin@sogang.ac.kr
}

In this special issue of International Neurourology Journal (INJ), we would like to introduce new equipment and devices. The valuable articles recruited for publication in this issue illustrate possibilities of for the development of new therapeutic technologies.

Microfluidics is the field of science and technology that deals with fluids on very small scales, usually in the range of microliters $\left(10^{-6} \mathrm{~L}\right)$ to picoliters $\left(10^{-12} \mathrm{~L}\right)$; it has several advantages, including the low consumption of samples, a short analysis time, and high sensitivity $[1,2]$. Microfluidic devices for urological research are introduced in this issue. The authors show that microfluidic devices are a useful technology for detecting prostate and bladder cancers and characterizing cancer microenvironments [3]. Applications in biomarker detection, urine nanofluidics, and sperm analysis are natural extensions of this technology. Microfluidics has been used to design nanoparticles that identify specific transmembrane antigens, such as prostate-specific membrane antigen, suggesting the possibility of ultrafine targeted therapies [4]. While the current technology mostly allows for planar photolithographic designs that limit microfluidic circuitry to serpentine networks, at best, 3-dimensional printed microfluidic designs are already in development $[5,6]$. This will enable additional control and complexity. The importance of these single-cell applications is not only that they have the novel aspect of addressing the cell itself, instead of the surrounding tissue, but that they clearly have the capacity to exert extremely fine control over biological environments. In some applications, it has already been estimated that fine control through microfluidics exceeds what can be accomplished via the robotic handling of fluids [7]. Considering that one branch of microfluidics, optofluidics has demonstrated the capability to sort particles, the future use of microfluidics may focus less on precision, and more on expanding its applications in novel ways $[8,9]$.

Mesenchymal stem cells (MSCs) are a promising source of stem cells for the regeneration of damaged cells and tissues. MSCs can be easily isolated from a variety of tissues in the human body, such as from bone marrow, umbilical cord, and adipose tissue, among others $[10,11]$. The differentiation properties of stromal cells, such as bone marrow-derived stromal cells, umbilical cord-derived stromal cells, and adipose-derived stromal cells, and correlations with their intrinsic mechanical properties are also presented in this issue [12]. The findings of this study will be helpful for organ reconstruction.

Voltage-controlled electrical stimulation, such as electroporation, applies electric pulses at a high intensity to enhance cell membrane permeability [13]. In an article published in this issue, the electric field of biological tissues during voltage-controlled electrical stimulation was characterized. The authors constructed a realistic electric field map of muscle tissue by enhancing the anisotropy of the tissue using a relationship between the diffusion tensor and conductivity tensor [14].

Dexmedetomidine is an $\alpha 2$-adrenergic agonist that is used to promote postoperative and intensive care sedation and analgesia [15]. Park et al. [16] developed an oral mucosa patch using dexmedetomidine for sedation. This patch will be valuable in the dental field and for urological and gynecological procedures that cause patients to experience vague fears, and especially for 
children.

INJ aims to expand and disseminate knowledge, and to explore the possibility of developing new therapeutic techniques. These efforts of INJ will facillate the development of new treatments for intractable diseases, including urological diseases, and will assist in developing more effective treatment techniques. The Editorial Board of INJ would like to express its gratitude to the authors for the outstanding articles that they submitted to this special issue of INJ.

- Conflict of Interest: No potential conflict of interest relevant to this article was reported.

\section{REFERENCES}

1. Whitesides GM. The origins and the future of microfluidics. Nature 2006;442:368-73.

2. Feng $X$, Du W, Luo Q, Liu BF. Microfluidic chip: next-generation platform for systems biology. Anal Chim Acta 2009;650:83-97.

3. Han SJ, Park HK, Kim KS. Applications of microfluidic devices for urology. Int Neurourol J 2017;21 Suppl 1:S4-9.

4. Farokhzad OC, Khademhosseini A, Jon S, Hermmann A, Cheng J, Chin C, et al. Microfluidic system for studying the interaction of nanoparticles and microparticles with cells. Anal Chem 2005;77: 5453-9.

5. Bhattacharjee N, Urrios A, Kang S, Folch A. The upcoming 3Dprinting revolution in microfluidics. Lab Chip 2016;16:1720-42.

6. Ho CM, Ng SH, Li KH, Yoon YJ. 3D printed microfluidics for biological applications. Lab Chip 2015;15:3627-37.

7. Dittrich PS, Manz A. Lab-on-a-chip: microfluidics in drug discov- ery. Nat Rev Drug Discov 2006;5:210-8.

8. Psaltis D, Quake SR, Yang C. Developing optofluidic technology through the fusion of microfluidics and optics. Nature 2006;442: 381-6.

9. Whitesides GM. The origins and the future of microfluidics. Nature 2006;442:368-73.

10. Peng L, Jia Z, Yin X, Zhang X, Liu Y, Chen P, et al. Comparative analysis of mesenchymal stem cells from bone marrow, cartilage, and adipose tissue. Stem Cells Dev 2008;17:761-73.

11. Shafiee A, Seyedjafari E, Soleimani M, Ahmadbeigi N, Dinarvand P, Ghaemi N. A comparison between osteogenic differentiation of human unrestricted somatic stem cells and mesenchymal stem cells from bone marrow and adipose tissue. Biotechnol Lett 2011; 33:1257-64.

12. Han I, Kwon BS, Park HK, Kim KS. Differentiation potential of mesenchymal stem cells is related to their intrinsic mechanical properties. Int Neurourol J 2017;21 Suppl 1:S24-31.

13. Kranjc M, Markelc B, Bajd F, Čemažar M, Serša I, Blagus T, et al. In situ monitoring of electric field distribution in mouse tumor during electroporation. Radiology 2015;274:115-23.

14. Choi BK, Oh TI, Sajib SZ, Kim JW, Kim, HJ, Kwon OI, et al. Realistic electric field mapping of anisotropic muscle during electrical stimulation using a combination of water diffusion tensor and electrical conductivity. Int Neurourol J 2017;21 Suppl 1:S32-8.

15. Paris A, Tonner PH. Dexmedetomidine in anaesthesia. Curr Opin Anaesthesiol 2005;18:412-8.

16. Park JH, Ko IG, Kim SE, Jin JJ, Hwang L, Kim CJ, et al. Dexmedetomidine oral mucosa patch for sedation suppresses apoptosis in hippocampus of normal rats. Int Neurourol J 2017;21 Suppl 1:S39-47. 